\title{
Criptógamos do Parque Estadual das Fontes do Ipiranga, São Paulo, SP. Algas, 18: Chlorophyceae (Volvocales)
}

\author{
CARLOS E.M. BICUDO ${ }^{1}$
}

(recebido: 22 de janeiro de 2003; aceito: 30 de outubro de 2003)

\begin{abstract}
Cryptogams of the "Parque Estadual das Fontes do Ipiranga", São Paulo, SP. Algae, 18: Chlorophyceae (Volvocales)). Paper is the survey of the order Volvocales in the Parque Estadual das Fontes do Ipiranga Biological Reserve, city of São Paulo, São Paulo State, Brazil. Seven genera (Carteria, Chlamydomonas, Chlorogonium, Chloromonas, Coccomonas, Pandorina, and Pteromonas), with a total of 26 species are identified. Carteria with nine species is the genus with the largest number of taxa in the area, followed by Chlamydomonas with 7, Chlorogonium with 4, Chloromonas and Pteromonas with 2 each, and Coccomonas and Pandorina with a single one. Carteria hiemale Skvortzov, C. lunzensis Pascher \& Jahoda, C. plana Pascher, C. wisconsinensis Huber-Pestalozzi, Chlorogonium fusiforme Matvienko and C. gracile Matvienko are the best represented species geographically, occurring in 2 localities each.
\end{abstract}

Key words - Brazil, Chlorophyceae, Volvocales

RESUMO - (Criptógamos do Parque Estadual das Fontes do Ipiranga, São Paulo, SP. Algas, 18: Chlorophyceae (Volvocales)). Trabalho é o levantamento florístico da ordem Volvocales na Reserva Biológica do Parque Estadual das Fontes do Ipiranga situado na cidade de São Paulo, estado de São Paulo, Brasil. Sete gêneros (Carteria, Chlamydomonas, Chlorogonium, Chloromonas, Coccomonas, Pandorina e Pteromonas) e 26 espécies foram identificados. Carteria com nove espécies foi o gênero mais bem representado na área, seguido de Chlamydomonas com sete, Chlorogonium com quatro, Chloromonas e Pteromonas com duas cada e Coccomonas e Pandorina com uma espécie cada. Carteria hiemale Skvortzov, C. lunzensis Pascher \& Jahoda, C. plana Pascher, C. wisconsinensis Huber-Pestalozzi, Chlorogonium fusiforme Matvienko e C. gracile Matvienko foram as espécies mais bem representadas do ponto de vista de suas distribuições geográficas, pois cada uma ocorreu em duas localidades no parque.

Palavras-chave - Brasil, Chlorophyceae, Volvocales

\section{Introdução}

Referências à ocorrência de representantes de Volvocales na Reserva Biológica do Parque Estadual das Fontes do Ipiranga (PEFI) são escassas, somam 13 e estão divididas em dois grupos bem distintos quanto ao nível da informação fornecida. O primeiro grupo é formado por seis trabalhos eminentemente taxonômicos, que incluem descrição e ilustração dos materiais identificados. O segundo por sete trabalhos do tipo ecológico, que apenas citam as espécies em relações dos materiais identificados.

Skvortzov (1967) é a primeira referência à ocorrência de Volvocales no PEFI. O trabalho consta de três notas, na primeira das quais, estudando cultivo de material subaéreo coletado entre musgos e hepáticas de um tronco de árvore na área da reserva, o autor propôs o gênero Silvamonas, com a única espécie S. lobata Skvortzov. Na segunda, Skvortzov (1967)

1. Instituto de Botânica, Seção de Ecologia, Caixa Postal 4005, 01061-970 São Paulo, SP, Brasil. cbicudo@terra.com.br descreveu e propôs duas espécies novas de Sphaerella, S. papillata Skvortzov e S. saupaulensis Skvortzov, a partir de material coletado entre plantas de Mayaca sp., em um estancado temporário. O referido autor não ofereceu, entretanto, maior detalhe sobre a localização do corpo d'água no parque. Na terceira nota, Skvortzov (1967) propôs cinco espécies de Chlamydomonas, porém, nenhuma descrita de material brasileiro, mas proveniente do Jardim Botânico de Durban, na África do Sul.

A referência seguinte é o trabalho de Skvortzov \& Noda (1967), em que são citadas oito espécies de Chlorogonium para o estado de São Paulo (não nove como os autores mencionaram no texto), quatro das quais (C. utriculariae Skvortzov \& Noda, C. nodeana Skvortzov, C. matvienkoi Skvortzov \& Noda e C. sanpaulensis Skvortzov \& Noda) foram identificadas a partir de material do PEFI.

Skvortzov \& Noda (1969) propuseram dois gêneros (Strömia e Tentaculomonas), o primeiro com duas espécies ( $S$. brasiliana Skvortzov \& Noda e S. subsphaerica Skvortzov \& Noda) e o último com uma ( $T$. natans Skvortzov \& Noda) e a família 
Strömiadaceae a partir de material coletado de um estancado, sem definir qual, no PEFI.

Skvortzov (1970) e Skvortzov \& Noda (1981) possuem exatamente o mesmo conteúdo. Em ambos são descritas 19 espécies de Carteria, das quais 15 foram documentadas do estudo de materiais do PEFI e 13 foram propostas como novas para a Ciência.

As descrições das espécies em todos os trabalhos são razoavelmente ricas em detalhes morfológicos e medidas, bem como o são as ilustrações fornecidas. Entretanto, os referidos autores jamais localizaram com precisão os ambientes de proveniência dos materiais estudados. A informação que forneceram dos locais de origem das unidades amostrais estudadas é bastante imprecisa em todos os trabalhos.

Os trabalhos de cunho ecológico incluem referências a Volvocales nas listas das algas identificadas para os locais de estudo. Exceto Tucci (2002), não consta desses trabalhos descrição nem ilustração dos materiais identificados.

A partir de amostras do Lago do Instituto de Astronomia, Geofísica e Ciências Atmosféricas (ex Instituto Astronômico e Geofísico), Lopes (1999) identificou sete espécies de Volvocales [Carteria sp., Chlamydomonas planctonica Skuja, Chlamydomonas sordida Ett1, Chlamydomonas sp., Coccomonas orbicularis Stein, Pteromonas sp. e Pandorina morum (O.F. Muller) Bory] e Vercellino (2001) quatro [Carteria multifilis (Fresenius) Dill, Chlamydomonas planctogloea Skuja, Chlamydomonas sordida Ettl e Chlamydomonas sp.].

Moura (1996) identificou Chlamydomonas sp. 1 e Chlamydomonas sp. 2 do estudo de material do Lago das Garças. Para o mesmo reservatório, Vercellino (2001) documentou a ocorrência de quatro espécies [Chlamydomonas planctogloea Skuja, Chlamydomonas sordida Ettl, Chlamydomonas sp. e Chlamydomonadopsis elliptica (Koršikov) Fott], Gentil (2000) e Crossetti (2002) identificaram Chlamydomonas sp. e Tucci (2002) três espécies aparentemente distintas de Chlamydomonas, as quais denominou Chlamydomonas sp. 1, Chlamydomonas sp. 2 e Chlamydomonas sp. 3. Destas três, apenas Chlamydomonas sp. 1 foi ilustrada.

Finalmente, embora B.V. Skvortzov e M. Noda tenham mencionado em alguns trabalhos que os espécimes-tipo das novidades taxonômicas propostas se encontram preservados e depositados na Seção de Criptógamos, da qual foi desmembrada a Seção de Ficologia, na verdade jamais o foram. Não existe nem nunca existiu material de qualquer dessas espécies, muito menos material-tipo, depositado no Herbário Científico do Estado "Maria Eneyda P. Kauffmann Fidalgo" (SP).

\section{Material e métodos}

Os métodos gerais do trabalho constam no planejamento da flora (Milanez et al. 1990).

O material foi coletado aleatoriamente e os procedimentos de coleta constam em Fidalgo \& Bononi (1984).

Os táxons cujo nome aparece indicado com asterisco no texto e nas chaves de identificação não foram reencontrados durante o presente levantamento. Constam apenas da literatura.

Famílias, gêneros dentro das famílias e espécies dentro dos gêneros foram relacionados em ordem alfabética para sua mais pronta localização.

\section{Resultados e Discussão}

Sete gêneros de Volvocales foram identificados de amostras de água do PEFI e suas situações sistemáticas são as seguintes segundo Bourrelly (1972):

Volvocales

Chlamydomonadaceae

Carteria

Chlamydomonas

Chlorogonium

Chloromonas

Phacotaceae

Coccomonas

Pteromonas

Volvocaceae

Pandorina

Chlamydomonadaceae

Carteria Diesing emend. Francé

Indivíduo monadóide, em geral de hábito solitário e vida livre, raro epibionte. A célula mostra grande variedade de formas em vista frontal (taxonômica), podendo apresentar-se esférica, elipsóide, ovóide, gutuliforme, fusiforme ou próximo do cilíndrico. Em raros casos, pode ser dorsiventralmente achatada ou arqueada. A parede celular é mais ou menos espessa, bastante conspícua, podendo ou não apresentar a região anterior diferenciada numa papila que pode, às vezes, ser extremamente conspícua. O cloroplasto é único, urceolado e pode ter o bordo liso ou radialmente inciso, exceto em Carteria polychloris e C. hiemale, onde 
ocorrem vários cloroplastos discóides. Os pirenóides variam, quanto ao número, de um a vários, podem ter localização axial mediana ou basal e são revestidos por uma capa formada por numerosos grãos de amido. Os quatro flagelos possuem tamanhos iguais entre si, são homodinâmicos, inserem-se anterior e apicalmente na célula e apresentam disposição cruciada. Freqüentemente, ocorrem dois vacúolos contráteis apicais por célula e um diminuto estigma.
Ettl (1958) retirou do gênero Carteria as espécies que apresentam numerosos vacúolos contráteis dispersos no citoplasma e constituiu, com elas, o gênero Pseudocarteria. Alguns autores consideram o número de vacúolos contráteis por célula uma característica de considerável peso diagnóstico e, por isso, concordam com Ettl (1958). Os demais não creditam tal peso ao número de vacúolos por célula e, por isso, não aceitam o gênero Pseudocarteria.

Chave para as espécies

1. Célula com estigma

2. Cloroplastos numerosos, discóides

7. C. polychloris

2. Cloroplasto 1 , urceolado

3. Célula esférica ou quase

4. Pirenóide pequeno, esférico 1. C. globulosa*

4. Pirenóide grande, esférico ou transversalmente elíptico

5. Pólo anterior da célula com papila hemisférica 4. C. multifilis

5. Pólo anterior da célula destituído de papila 8. C. sanpaulensis

3. Célula elipsóide, elipsóide-cilíndrica a oblonga

6. Papila ampla, pouco proeminente; pirenóide grande

6. C. platyrhyncha*

6. Papila cônica a hemisférica, bastante proeminente; pirenóide pequeno

7. Célula elipsóide-cilíndrica, quase oblonga 3. C. lunzensis*

7. Célula amplamente elipsóide 5. C. plana*

1. Célula sem estigma

8. Cloroplastos numerosos, discóides 2. C. hiemale*

8. Cloroplasto 1, urceolado 9. C. winconsinensis

1. Carteria globulosa* Pascher, Süßwasserfl. Deutschl., Österr. Schweiz 4:143, fig. 89b. 1927.

= Carteria globosa Koršikov \& Skvortzov, Bol. Soc. La Libertad 2:7, fig. 9-10. 1970; Skvortzov \& Noda, Sci. Rep. Niigata Univ., Ser. D, 4:29, fig. 9-10. 1981. Figuras 1-2.

Célula esférica a levemente elipsóide, não achatada dorsiventralmente, $14,7-16,1 \times 11-12 \mu \mathrm{m}, \mathrm{R} \mathrm{c} / 1=1-1,1$; parede celular fina, pólo anterior destituído de papila; flagelos ca. 1,5 vez mais longos que a célula; cloroplasto urceolado, quase alcançando a base dos flagelos, amplamente aberto, porção basal atingindo só o quarto basal do comprimento da célula, pirenóide 1, pequeno, esférico, situado na porção basal do cloroplasto; estigma pequeno, punctiforme, situado no quarto anterior da célula; vacúolos pulsáteis 2 , anteriores.

Hábitat: planctônica num dreno no Jardim Botânico de São Paulo, sem especificar qual nem onde.

Material examinado: Skvortzov, Bol. Soc. Bot. La Libertad 2: 7. 1970; Skvortzov \& Noda, Sci. Rep. Niigata Univ., Ser. D, 4: 29. 1981.
No caso das formas esféricas, Carteria globulosa Pascher e C. globosa Koršikov diferem, basicamente, pelas dimensões celulares, pois os representantes da primeira espécie medem $8-12 \mu \mathrm{m}$ de diâmetro enquanto os da segunda, 18-28 $\mu \mathrm{m}$. Existe também diferença quanto à forma do cloroplasto, que é relativamente mais aberto em C. globulosa Pascher do que em C. globosa Koršikov. Tanto pelas medidas celulares quanto pelo tipo de cloroplasto, os exemplares em Skvortzov (1970) e Skvortzov \& Noda (1981) são representantes de C. globulosa Pascher.

2. Carteria hiemale* Skvortzov, Bol. Soc. Bot. La Libertad 2:6, fig. 2. 1970 ex C. Bicudo. Lectótipo, aqui designado: Skvortzov, Bol. Soc. Bot. La Libertad 2: fig. 2. 1970.

$=$ Carteria hiemale Skvortzov \& Noda, Sci. Rep. Niigata Univ., Ser. D, 4:29, fig. 2. 1981.

Figura 3.

Célula esférica, não achatada dorsiventralmente, 7,4-15 $\mu \mathrm{m}$ diâm., $\mathrm{R}$ c/l = ca. 1; parede celular bastante 
espessa, pólo anterior destituído de papila; flagelos ca. 1,5 vez mais longos que a célula; cloroplastos discóides, numerosos, parietais, pirenóide ausente; estigma ausente; vacúolos pulsáteis 2 , anteriores.

Hábitat: planctônica no Lago das Ninféias e num dreno no Jardim Botânico de São Paulo, sem especificar qual nem onde.

Material examinado: Skvortzov \& Noda, Sci. Rep. Niigata Univ., Ser. D, 4: 29. 1981.

Skvortzov (1970) propôs Carteria hiemale sem designar-lhe o tipo nomenclatural. Inusitadamente, Skvortzov \& Noda (1981) propuseram novamente a espécie e, mais uma vez, deixaram de designar seu tipo nomenclatural. Tanto o material examinado, quanto a descrição e a ilustração da espécie são exatamente os mesmos em ambos os trabalhos.

Carteria hiemale Skvortzov difere de Carteria polychloris Pascher, a única outra espécie do gênero cujos cloroplastos são discóides, numerosos e parietais, pela célula esférica e pelas menores dimensões celulares.

Designamos, presentemente, lectótipo da espécie a ilustração original de Carteria hiemale em Skvortzov (1970) pretendendo, dessa forma, validar o nome da espécie conforme o art. 9.2 do Código Internacional de Nomenclatura Botânica (Greuter et al. 2000).

3. Carteria lunzensis* Pascher \& Jahoda, Arch. Potistenk. 61:251, fig. 6. 1928.

$=$ Carteria aquae-fluitans Skvortzov, Bol. Soc. Bot. La Libertad 2:8, fig. 14. 1970.

= Carteria aquae-fluitans Skvortzov \& Noda, Sci. Rep. Niigata Univ., Ser. D, 4:30, fig. 14. 1981.

$=$ Carteria subovata Skvortzov, Bol. Soc. Bot. La Libertad 2:8, fig. 15-16. 1970.

$=$ Carteria subovata Skvortzov \& Noda, Sci. Rep. Niigata Univ., Ser. D, 4:30, fig. 15-16. 1981.

Figuras 4-6.

Célula elipsóide-cilíndrica a praticamente oblonga, achatada dorsiventralmente, pólos amplamente arredondados, (5,7-)12,8-15,4 × (3-)7,4-12 $\mu \mathrm{m}$, $\mathrm{R} \mathrm{c} / 1=1,3-1,9$; parede celular fina, pólo anterior com papila cônica; flagelos 1-1,5 vez mais longos que a célula; cloroplasto urceolado, alcançando o quinto anterior da célula ou até quase a papila anterior, amplamente aberto, porção basal atingindo o quarto ou quinto basal do comprimento da célula, pirenóide 1, pequeno, esférico, situado na porção basal do cloroplasto; estigma pequeno, elíptico a linear, situado no terço anterior da célula; vacúolos pulsáteis 2 , anteriores.

Hábitat: planctônica no Lago dos Cisnes e num estancado temporário no Jardim Botânico de São Paulo, sem especificar qual nem onde.

Material examinado: Skvortzov, Bol. Soc. Bot. La Libertad 2:8. 1970; Skvortzov \& Noda, Sci. Rep. Niigata Univ., Ser. D, 4:30. 1981.

Os exemplares de Carteria aquae-fluitans e C. subovata em Skvortzov (1970) e Skvortzov \& Noda (1981) em nada diferem dos de C. lunzensis Pascher \& Jahoda, razão pela qual os consideramos idênticos entre si e sinônimos heterotípicos.

Foi encontrado um indivíduo apenas medindo 5,7 $\times$ $3 \mu \mathrm{m}$. Exceto pelas medidas, que são bastante discrepantes dos limites métricos da última espécie em literatura $(11-22 \times 7-11 \mu \mathrm{m})$, este espécime coincidiu inteiramente com a circunscrição de Carteria lunzensis Pascher \& Jahoda. Preferimos, por isso, considerá-lo um exemplar extremo, em termos de medidas, da referida espécie.

4. Carteria multifilis (Fresenius) Dill, Jahrb. Wiss. Bot. 28:341, pl. 5, fig. 51. 1895.

Figura 7.

Célula amplamente elipsóide a quase esférica, não achatada dorsiventralmente, pólos amplamente arredondados, ca. $13 \times 12 \mu \mathrm{m}, \mathrm{R}$ c/l = ca. 1,1 ; parede celular moderadamente a bastante espessa, pólo anterior com papila hemisférica; flagelos 1,5-2 vezes mais longos que a célula; cloroplasto poculiforme, alcançando a papila anterior, amplamente aberto, porção basal atingindo metade do comprimento da célula, pirenóide 1, grande, esférico ou transversalmente elipsóide, situado na porção basal do cloroplasto; estigma pequeno, situado no terço anterior da célula; vacúolos pulsáteis 2 , anteriores.

Hábitat: perifítica no Lago do Instituto de Astronomia, Geofísica e Ciências Atmosféricas.

Material examinado: BRASIL: SÃo PAUlo: São Paulo, Parque Estadual das Fontes do Ipiranga, Lago do IAG, 1-VI-1997, R.Y. Honda s.n. (SP355512).

5. Carteria plana* Pascher, Süßwasserfl. Deutschl., Österr. Schweiz 4:153, fig. 103. 1927.

$=$ Carteria pyrenoidea Skvortzov, Bol. Soc. Bot. La Libertad 2:8, fig. 13. 1970.

$=$ Carteria pyrenoidea Skvortzov \& Noda, Sci. Rep. Niigata Univ., Ser. D, 4:30, fig. 13. 1981.

$=$ Carteria micronucleolata Koršikov f. Skvortzov, Bol. Soc. Bot. La Libertad 2:8, fig. 18. 1970.

= Carteria micronucleolata Koršikov f. Skvortzov \& Noda, Sci. Rep. Niigata Univ., Ser. D, 4:30, fig. 18. 1981. Figuras 8-9. 
Célula elipsóide, bastante achatada dorsiventralmente, pólos acuminado-arredondados, 14,5-18 × 9-12 $\mu \mathrm{m}, \mathrm{R} \mathrm{c} / 1=1,4-2$; parede celular fina, pólo anterior com papila cônica, quase hemisférica; flagelos ca. 1,5 vez mais longos que a célula; cloroplasto urceolado, alcançando o quarto superior até quase a papila anterior, amplamente aberto, porção basal atingindo desde um quarto até três quartos do comprimento da célula, pirenóide 1 , pequeno, esférico, situado na porção basal do cloroplasto; estigma pequeno, mais ou menos linear, situado no terço anterior da célula; vacúolos pulsáteis 2 , anteriores.

Hábitat: planctônica num estancado temporário no Jardim Botânico de São Paulo, sem especificar qual nem onde e num dreno no Jardim Botânico de São Paulo, também sem especificar qual nem onde.

Material examinado: Bol. Soc. Bot. La Libertad 2:8. 1970; Skvortzov \& Noda, Sci. Rep. Niigata Univ., Ser. D, 4:30. 1981.

Não foi possível diferir os representantes de Carteria plana Pasher dos de C. pyrenoidea em Skvortzov (1970) e Skvortzov \& Noda (1981), razão pela qual os consideramos sinônimos heterotípicos.

Os espécimes de Carteria micronucleolata Koršikov f. em Skvortzov (1970) e em Skvortzov \& Noda (1981) são, morfologicamente, idênticos aos de C. plana Pascher. Por esta razão, consideramo-los sinônimos do ponto de vista nomenclatural (isotípicos).

6. Carteria platyrhyncha* Ettl in Komárek \& Ettl, Algol. Stud. 281, fig. 37. 1958.

= Carteria oculata Skvortzov, Bol. Soc. Bot. La Libertad 2:7, fig. 12. 1970.

= Carteria oculata Skvortzov \& Noda, Sci. Rep. Niigata Univ., Ser. D, 4:30, fig. 12. 1981.

Figura 10.

Célula elipsóide a quase oblonga, não achatada dorsiventralmente, pólo anterior mais ou menos acuminado, pólo posterior amplamente arredondado, 7,49,3 × 5,7-7 $\mu \mathrm{m}, \mathrm{R} \mathrm{c} / 1=$ ca. 1,3 ; parede celular fina, pólo anterior com papila ampla, pouco proeminente; flagelos 1-1,5 vez mais longos que a célula; cloroplasto urceolado, quase alcançando a papila anterior, amplamente aberto, porção basal mal atingindo a metade basal do comprimento da célula, pirenóide 1, grande, esférico, situado na porção basal do cloroplasto; estigma grande, elíptico, situado no terço anterior da célula; vacúolos pulsáteis 2, anteriores.

Hábitat: planctônica num estancado temporário no Jardim Botânico de São Paulo, sem especificar qual nem onde.
Material examinado: Skvortzov, Bol. Soc. Bot. La Libertad 2:7. 1970; Skvortzov \& Noda, Sci. Rep. Niigata Univ., Ser. D, 4:30. 1981.

Não existe diferença entre os representantes de Carteria platyrhyncha Ettl, C. oculata Skvortzov e C. oculata Skvortzov \& Noda. Por essa razão, consideramos os exemplares em Skvortzov (1970) e Skvortzov \& Noda (1981) sinônimos de C. platyrhyncha Ettl.

7. Carteria polychloris Pascher, Sü $\beta$ wasserfl. Deutschl., Österr. Schweiz 4:158, fig. 110. 1927.

= Carteria discoidea Skvortzov, Bol. Soc. Bot. La Libertad 2:5, fig. 1. 1970.

= Carteria discoidea Skvortzov \& Noda, Sci. Rep. Niigata Univ., Ser. D, 4:28, fig. 1. 1981.

Figura 11.

Célula amplamente elipsóide a quase esférica, raro amplamente ovóide, não achatada dorsiventralmente, pólos amplamente arredondados, 17-22 × 19-22 $\mu \mathrm{m}$, $\mathrm{R} \mathrm{c} / 1=$ ca. 1,1 ; parede celular moderadamente a bastante espessa, pólo anterior com papila hemisférica; flagelos 1,5-2 vezes mais longos que a célula; cloroplastos discóides, numerosos, parietais, pirenóide ausente; estigma grande, mais ou menos linear, situado no terço anterior da célula; vacúolos pulsáteis 2 , anteriores.

Hábitat: planctônica no Lago das Ninféias.

Material examinado: BRASIL: São PAUlo: São Paulo, Parque Estadual das Fontes do Ipiranga, Lago das Ninféias, 5-VII-1973, C.R. Leite s.n. (SP130453); 4-VI-1975, C.R. Leite s.n. (SP130973); 21-III-2001, L.R. Godinho \& S.P. Schetty S.n. (SP355407).

Skvortzov (1970) propôs Carteria discoidea sem indicar o tipo nomenclatural. Onze anos depois, os mesmos autores (Skvortzov \& Noda, 1981) propuseram novamente a espécie e, mais uma vez, sem lhe indicar o tipo nomenclatural. Material examinado, descrição e ilustração da espécie são exatamente os mesmos nos dois trabalhos. Em ambos os trabalhos acima, os autores compararam a nova espécie com $C$. polychloris Pascher e afirmaram que seriam diferentes graças ao maior tamanho das células de $C$. discoidea e aos seus cloroplastos também maiores. Se por um lado os cloroplastos são pouco maiores em $C$. discoidea e, conseqüentemente, pouco menos numerosos, por outro lado as dimensões celulares não são maiores, pois C. polychloris pode medir de 16-22 × 11-16 $\mu \mathrm{m}$. Nestas condições, preferimos considerar $C$. discoidea Skvortzov e C. discoidea Skvortzov \& Noda sinônimos de C. polychloris Pascher. 
8. Carteria sanpaulensis Skvortzov, Bol. Soc. Bot. La Libertad 2:7, fig. 6-8. 1970 ex C. Bicudo. Lectótipo, aqui designado: Skvortzov, Bol. Soc. Bot. La Libertad 2: fig. 6-8. 1970.

$=$ Carteria saopaulensis Skvortzov \& Noda, Sci. Rep. Niigata Univ., Ser. D, 4:29, fig. 6-8. 1981.

Figuras 12-14.

Célula esférica ou quase, não achatada dorsiventralmente, $11-22 \mu \mathrm{m}$ diâm., $\mathrm{R} \mathrm{c} / \mathrm{l}=$ ca. 1 ; parede celular espessa, pólo anterior destituído de papila; flagelos ca. 1,5 vez mais longos que a célula; cloroplasto urceolado, alcançando o pólo anterior, pouco aberto, porção basal atingindo mais ou menos três quartos do comprimento da célula, pirenóide 1, grande, esférico ou quase, situado na porção aproximadamente mediana da célula; estigma grande, elíptico, situado no terço anterior da célula; vacúolos pulsáteis 2 , anteriores.

Hábitat: planctônica no Lago das Ninféias.

Material examinado: BRASIL: São PAulo: São Paulo, Parque Estadual das Fontes do Ipiranga, Lago das Ninféias, 15-III-2001, L.R. Godinho \& S.P. Schetty s.n. (SP355407).

Skvortzov (1970) propôs Carteria sanpaulensis (grafia original saopaulensis) sem designar o tipo nomenclatural. Skvortzov \& Noda (1981) propuseram outra vez a mesma espécie (grafia original saopaulensis) sem, de novo, designar seu tipo nomenclatural. Material examinado, descrição e ilustração da espécie são idênticos em ambos os trabalhos. C. sanpaulensis Skvortzov pode, por possuir célula esférica destituída de papila anterior, ser confundida com C. globosa Koršikov e C. globulosa Pascher. Entretanto, difere da primeira pela situação central do pirenóide e da última pelas maiores dimensões celulares.

Designamos, presentemente, lectótipo da espécie as ilustrações originais de Carteria sanpaulensis em Skvortzov (1970) pretendendo, dessa forma, validar o nome da espécie conforme o art. 9.2 do Código Internacional de Nomenclatura Botânica (Greuter et al. 2000).

9. Carteria wisconsinensis Huber-Pestalozzi, Phytoplankt. Süßwassers. 5:90, fig. 64. 1961.

= Carteria abrupta Skvortzov, Bol. Soc. Bot. La Libertad 2:7, fig. 11. 1970.

= Carteria abrupta Skvortzov \& Noda, Sci. Rep. Niigata Univ., Ser. D, 4:30, fig. 11. 1981.

$=$ Carteria astigmata Skvortzov, Bol. Soc. Bot. La Libertad 2:8, fig. 17. 1970.
$=$ Carteria astigmata Skvortzov \& Noda, Sci. Rep. Niigata Univ., Ser. D, 4:30, fig. 17. 1981.

Figuras 15-16.

Célula elipsóide a pouco ovóide, não achatada dorsiventralmente, $10,2-12,7 \times 7,4-9,2 \mu \mathrm{m}, \mathrm{R} \mathrm{c} / 1=$ 1,3-1,5; parede celular grossa, pólo anterior destituído de papila; flagelos 1,5-2 vezes mais longos que a célula; cloroplasto urceolado, quase alcançando a base dos flagelos, amplamente aberto, porção basal atingindo a metade basal do comprimento da célula, pirenóide 1 , grande, esférico, situado na porção basal do cloroplasto; estigma ausente; vacúolos pulsáteis 2 , anteriores.

Hábitat: planctônica no Lago dos Cisnes e num dreno no Jardim Botânico de São Paulo sem especificar qual nem onde.

Material examinado: BRASIL: São Paulo: São Paulo, Parque Estadual das Fontes do Ipiranga, Lago dos Cisnes, 5-IX-1983, M.B. Xavier s.n. (SP176890).

Não existe diferença entre os representantes de Carteria wisconsinensis Huber-Pestalozzi e os de C. abrupta e C. astigmata. Por esta razão, consideramos os exemplares de ambas espécies em Skvortzov (1970) e Skvortzov \& Noda (1981) sinônimos heterotípicos de $C$. wisconsinensis HuberPestalozzi.

\section{Chlamydomonas Ehrenberg}

Indivíduo monadóide, de hábito solitário e vida livre. A célula mostra grande diversidade de forma em vista frontal (taxonômica), das quais a elipsóide e a ovóide são as mais comuns. Em alguns casos, a célula mostra marcada dorsiventralidade. A parede celular é sempre nítida, apresenta espessura variada e, na maioria das espécies, uma papila anterior mediana. $\mathrm{O}$ cloroplasto é parietal, único por célula e pode ser ciatiforme, urceolado, em forma de $\mathrm{H}$, em forma de calha, tubular ou, mais raramente, dividido em várias porções discóides. Podem ocorrer desde um até vários pirenóides, cuja situação no plasto é variada. Os dois flagelos possuem tamanhos iguais entre si, são homodinâmicos e inserem-se apicalmente no pólo anterior da célula. Os vacúolos contráteis aparecem em geral no pólo anterior da célula, mas também podem ocorrer irregularmente distribuídos por toda o protoplasma e seu número variar desde um até numerosos por célula. O estigma é bastante conspícuo, possui coloração avermelhada e situa-se mediana ou posteriormente no cloroplasto. 


\section{Chave para as espécies}

1. Cloroplasto em forma de $\mathrm{H}$ 1. C. agloëformis

1. Cloroplasto urceolado, em forma de taça ou calha

2. Cloroplasto em forma de calha

3. Célula elipsóide-ovóide a nitidamente ovóide 7. C. sordida

3. Célula elipsóide-cilíndrica, um tanto baciliforme 6. C. sagittula

2. Cloroplasto urceolado ou ciatiforme

4. Estigma situado na metade posterior da célula 5. C. planctogloea

4. Estigma situado no terço anterior da célula

5. Pirenóide situado no espessamento mais ou menos mediano do cloroplasto

5. Pirenóide situado na porção basal do cloroplasto

6. Célula 9-12 $\times 6-8,5 \mu \mathrm{m} ; \mathrm{R} \mathrm{c} / 1=1,3-2$ 4. C. gloeopara

6. Célula $6-8 \times 5-5,5 \mu \mathrm{m} ; \mathrm{R} \mathrm{c} / 1=1-1,1$ 2. C. debaryana 3. C. epibiotica

1. Chlamydomonas agloëformis Pascher, Süßwasserfl. Deutschl., Österr. Schweiz 4:252, fig. 206. 1927. Figura 17.

Célula elipsóide a amplamente ovóide, dorsiventralmente achatada e levemente arqueada, pólo anterior acuminado, pólo posterior amplamente arredondado, $11-19 \times 5-6,5 \mu \mathrm{m}, \mathrm{R} \mathrm{c} / 1=2,3-2,7$; parede celular fina, pólo anterior com papila acuminada; flagelos aproximadamente tão longos quanto a célula; cloroplasto em forma de $\mathrm{H}$, porções longitudinais relativamente espessas, abertas em ambos lados, porção transversal grossa, na altura da região mediana da célula, pirenóide 1, grande, situado na porção transversal do cloroplasto; estigma notavelmente grande, elíptico, situado na região mediana da célula, na altura do pirenóide; vacúolos pulsáteis 2, anteriores.

Hábitat: perifítica no Lago do Instituto de Astronomia, Geofísica e Ciências Atmosféricas.

Material examinado: BRASIL: São PAULo: São Paulo, Parque Estadual das Fontes do Ipiranga, Lago do IAG, 1-VI-1997, R.Y. Honda s.n. (SP355514).

Comentário: alguns exemplares ora examinados apresentaram comprimento pouco maior do que o descrito em Ettl (1983), que é de 8-15 × 4-12 $\mu \mathrm{m}$.

2. Chlamydomonas debaryana Goroschankin, Bull. Soc. Imp. Naturalistes Moscou, Nov. Sér. 5:106, pl. 1, fig. 9-12. 1891.

Figura 18.

Célula amplamente elipsóide (quase esférica), elipsóide a elipsóide-ovóide, não achatada dorsiventralmente, pólos anterior e posterior arredondados, o posterior mais amplamente arredondado, 9-12 $\times 6-8,5 \mu \mathrm{m}, \mathrm{R} \mathrm{c} / 1=1,3-2$; parede celular fina ou medianamente grossa, pólo anterior com papila grande, hemisférica; flagelos aproximadamente tão longos quanto a célula ou pouco mais longos; cloroplasto urceolado, alcançando a papila anterior, amplamente aberto, pirenóide 1, esférico ou elipsóide, grande, situado próximo do pólo celular posterior; estigma arredondado a elíptico, situado no terço anterior da célula; vacúolos pulsáteis 2, anteriores.

Hábitat: perifítica no Lago do Instituto de Astronomia, Geofísica e Ciências Atmosféricas.

Material examinado: BRASIL: São PAULO: São Paulo, Parque Estadual das Fontes do Ipiranga, Lago do IAG, 1-VI-1997, R.Y. Honda s.n. (SP355512).

3. Chlamydomonas epibiotica Ettl, Beih. Nova Hedwigia 49:330, pl. 22, fig. 1-2. 1976.

Figura 19.

Célula esférica a levemente ovóide, raro um tanto reniforme, não achatada dorsiventralmente, ambos pólos amplamente arredondados, 6-8 × 5-5,5 $\mu \mathrm{m}, \mathrm{R} \mathrm{c} / 1=1-1,1$; parede celular fina, pólo anterior com papila diminuta, acuminada; flagelos ca. 3 vezes mais longos que a célula; cloroplasto urceolado, alcançando a papila anterior, amplamente aberto, pirenóide 1, esférico, pequeno, situado próximo do pólo celular posterior; estigma circular a levemente elíptico, situado no terço anterior da célula; vacúolos pulsáteis 2 , anteriores.

Hábitat: perifítica no Lago do Instituto de Astronomia, Geofísica e Ciências Atmosféricas.

Material examinado: BRASIL: São PAULO: São Paulo, Parque Estadual das Fontes do Ipiranga, Lago do IAG, 1-VI-1997, R.Y. Honda s.n. (SP355512).

Chlamydomonas epibiotica é o nome novo proposto por Ettl (1976) para C. epiphytica G.M. Smith 1920, por este último ser homônimo posterior de C. epiphytica Koršikov 1917 e, por isso, um nome 

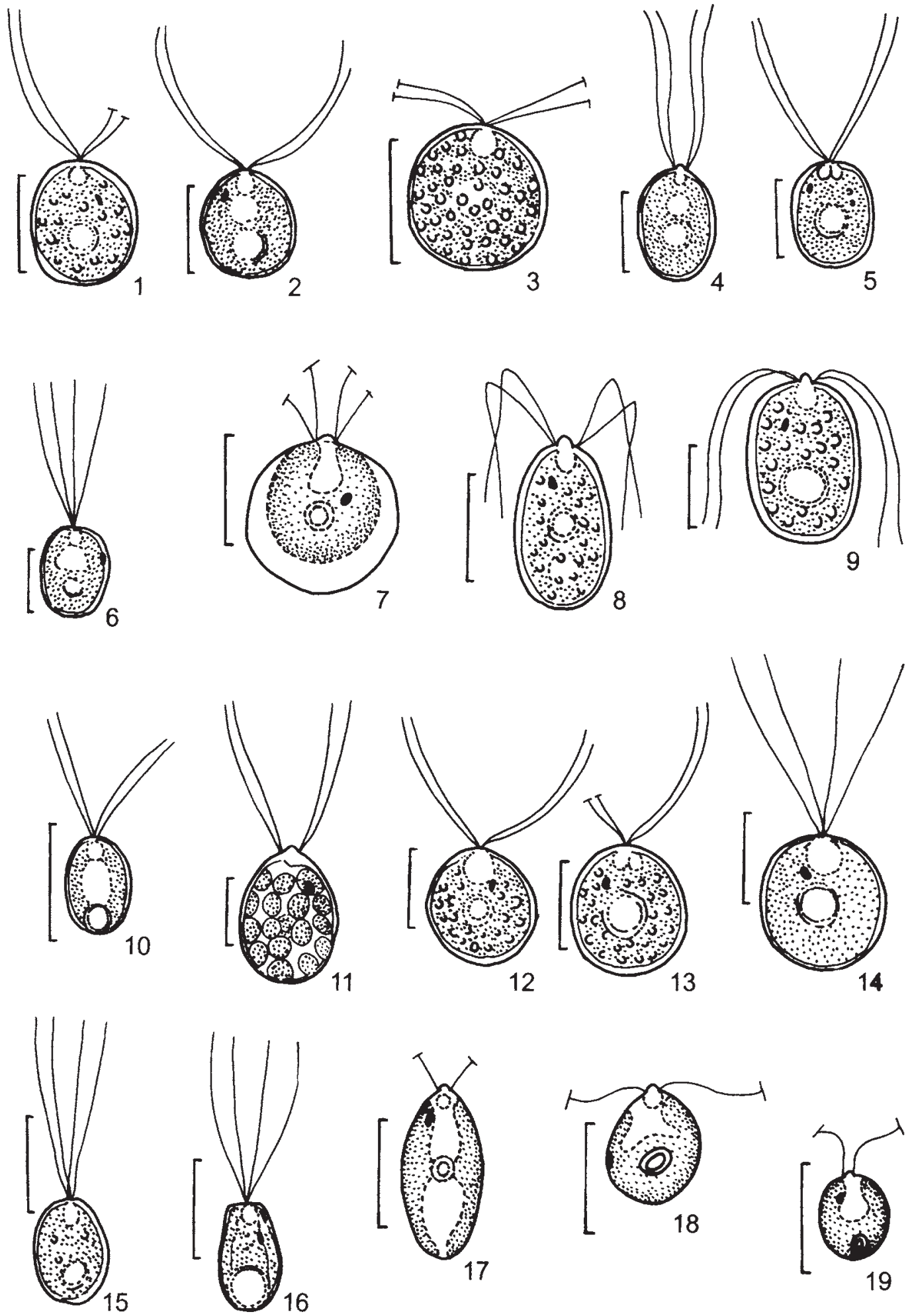

Figuras 1-19. Espécies de Volvocales do Parque Estadual das Fontes do Ipiranga. 1-2. Carteria globulosa Pascher (de Skvortzov \& Noda 1981). 3. Carteria hiemale Skvortzov ex C. Bicudo (de Skvortzov \& Noda 1981). 4-6. Carteria lunzensis Pascher \& Jahoda (de Skvortzov \& Noda 1981). 7. Carteria multifilis (Fresenius) Dill. 8-9. Carteria plana Pascher (de Skvortzov \& Noda 1981). 10. Carteria platyrhyncha Ettl (de Skvortzov \& Noda 1981). 11. Carteria polychloris Pascher (de Skvortzov \& Noda 1981). 12-14. Carteria sanpaulensis Skvortzov ex C. Bicudo (de Skvortzov \& Noda 1981). 15-16. Carteria wisconsinensis Huber-Pestalozzi (de Skvortzov \& Noda 1981). 17. Chlamydomonas agloëformis Pascher. 18. Chlamydomonas debaryana Goroschankin. 19. Chlamydomonas epibiotica Ettl. Barras $=10 \mu \mathrm{m}$. 
ilegítimo conforme o art. 53.1 do Código Internacional de Nomenclatura Botânica (Greuter et al. 2000).

4. Chlamydomonas gloeopara Rodhe \& Skuja in Skuja, Symb. Bot. Upsal. 9:81, pl. 8, fig. 1-9. 1948. Figura 20.

Célula mais ou menos amplamente elipsóide, raro cilíndrico-elipsóide, não achatada dorsiventralmente, ambos pólos amplamente arredondados, 10-12 $\times$ 4,5-5 $\mu \mathrm{m}, \mathrm{R} \mathrm{c} / 1=2-2,4$; parede celular fina, pólo anterior com papila arredondada; flagelos aproximadamente tão longos quanto a célula; cloroplasto urceolado, alcançando a papila anterior, 1 espessamento lateral na altura da metade do comprimento celular ou pouco posterior, pirenóide 1, esférico, situado no espessamento mais ou menos mediano do cloroplasto; estigma grande, esférico, situado no terço anterior da célula, relativamente próximo do pólo celular anterior; vacúolos pulsáteis 2 , anteriores.

Hábitat: perifítica no Lago do Instituto de Astronomia, Geofísica e Ciências Atmosféricas.

Material examinado: BRASIL: São PAULO: São Paulo, Parque Estadual das Fontes do Ipiranga, Lago do IAG, 1-VI-1997, R.Y. Honda s.n. (SP355514).

5. Chlamydomonas planctogloea Skuja, Nova Acta Regiae Soc. Sci. Upsal., Ser. 4, 16:135, pl. 19, fig. 4-5. 1956.

Figuras 21-22.

Célula amplamente ovóide, raro um tanto elipsóide, às vezes pouco assimétrica, não achatada dorsiventralmente, pólo anterior mais ou menos acuminado, pólo posterior amplamente arredondado, 3-6 $\times 2-4 \mu \mathrm{m}, \mathrm{R} \mathrm{c} / 1=1,1-1,5 ;$ parede celular muito fina, pólo anterior com papila arredondada; flagelos ca. 1,5 vez tão longos quanto a célula; cloroplasto ciatiforme, situado de um dos lados da célula; pirenóide 1, esférico, grande, situado na metade posterior da célula; estigma notavelmente grande, esférico, situado na metade anterior da célula; vacúolos pulsáteis 2 , anteriores.

Hábitat: perifitica e planctônica no Lago do Instituto de Astronomia, Geofísica e Ciências Atmosféricas.
Material examinado: BRASIL: São PAUlo: São Paulo, Parque Estadual das Fontes do Ipiranga, Lago do IAG, 1-VI-1997, R.Y. Honda s.n. (SP355512).

6. Chlamydomonas sagittula Skuja, Nova Acta Regiae Soc. Sci. Upsal., Ser. 4, 18:87, pl. 11, fig. 28. 1964. Figuras 23-24.

Célula elipsóide-cilíndrica, um tanto baciliforme, reta ou levemente arqueada, não achatada dorsiventralmente, pólo anterior mais ou menos acuminado, pólo posterior amplamente arredondado, 6-8 $\times 1,5-2 \mu \mathrm{m}, \mathrm{R} \mathrm{c} / 1=3-3,4$; parede celular muito fina, pólo anterior com papila acuminada; flagelos aproximadamente tão longos quanto a célula; cloroplasto em forma de calha, situado em um dos lados da célula; pirenóide 1, pequeno, esférico, situado mais ou menos na porção central da célula; estigma pequeno, aproximadamente esférico, situado no terço anterior da célula; vacúolos pulsáteis $1-2$, anteriores.

Hábitat: perifítica no Lago do Instituto de Astronomia, Geofísica e Ciências Atmosféricas.

Material examinado: BRASIL: São PAUlo: São Paulo, Parque Estadual das Fontes do Ipiranga, Lago do IAG, 1-VI-1997, R.Y. Honda s.n. (SP355514).

7. Chlamydomonas sordida Ettl, Arch. Protistenk. 108:381, fig. 75. 1965.

Figuras 25-26.

Célula elipsóide-ovóide a nitidamente ovóide, raro um pouco arqueada dorsiventralmente, ambos pólos amplamente arredondados ou pólo posterior mais amplamente arredondado que o anterior, 6,5-7,5 $\times$ 2,5-3,5 $\mu \mathrm{m}, \mathrm{R}$ c/1 = 2-2,8; parede celular fina, pólo anterior com papila grande, levemente acuminada a semicircular; flagelos aproximadamente tão longos quanto a célula; cloroplasto em forma de calha, situado em um dos lados da célula, porém envolvendo até mais de três quartos do diâmetro celular, com espessamento na metade posterior da célula onde se localiza o pirenóide; pirenóide 1, grande, esférico ou poligonalarredondado; estigma elíptico, situado no terço anterior da célula; vacúolos pulsáteis 2 , anteriores.

Figures 1-19. Volvocales species from the Parque Estadual das Fontes do Ipiranga. 1-2. Carteria globulosa Pascher (from Skvortzov \& Noda 1981). 3. Carteria hiemale Skvortzov ex C. Bicudo (from Skvortzov \& Noda 1981). 4-6. Carteria lunzensis Pascher \& Jahoda (from Skvortzov \& Noda 1981). 7. Carteria multifilis (Fresenius) Dill. 8-9. Carteria plana Pascher (from Skvortzov \& Noda 1981). 10. Carteria platyrhyncha Ettl (from Skvortzov \& Noda 1981). 11. Carteria polychloris Pascher (from Skvortzov \& Noda 1981). 12-14. Carteria sanpaulensis Skvortzov ex C. Bicudo (from Skvortzov \& Noda 1981). 15-16. Carteria wisconsinensis Huber-Pestalozzi (from Skvortzov \& Noda 1981). 17. Chlamydomonas agloëformis Pascher. 18. Chlamydomonas debaryana Goroschankin. 19. Chlamydomonas epibiotica Ettl. Bars $=10 \mu \mathrm{m}$. 
Hábitat: perifítica e planctônica no Lago do Instituto de Astronomia, Geofísica e Ciências Atmosféricas.

Material examinado: BRASIL: São PAULO: São Paulo, Parque Estadual das Fontes do Ipiranga, Lago do IAG, 1-VI-1997, R.Y. Honda s.n. (SP355514).

\section{Chlorogonium Ehrenberg}

Indivíduo monadóide, de hábito solitário e vida livre. A forma da célula em vista frontal (taxonômica) é, em geral, fusiforme alongada, raro elíptico-fusiforme. O pólo anterior é proeminente, sub-rostrado e possui extremidade arredondado-truncada. O pólo posterior é cônico e pontiagudo. A parede celular é fina, delicada, mas suficientemente rígida para manter constante a forma da célula. Não existe papila anterior mediana. $\mathrm{O}$ cloroplasto é único por célula, ocupa posição parietal na célula e reveste internamente a maior parte da parede celular, porém jamais alcança os pólos celulares. Em outras palavras, tem praticamente a forma da célula, mas também pode ser cilíndrico e oco, ter forma de calha, ser mais ou menos poculiforme ou até mesmo ter a forma de fita helicóide. Pode ou não ocorrer pirenóide. Quando o último ocorre, pode ser único e situar-se na porção mediana basal do plasto ou podem ocorrer vários pirenóides distribuídos aleatoriamente no plasto. Os dois flagelos possuem tamanhos iguais entre si e medem, no máximo, a metade do comprimento total da célula. São homodinâmicos e inserem-se anterior e apicalmente na célula. Vacúolos contráteis ocorrem sempre anteriormente na célula. Quando formam um par, ambos situam-se próximo da base dos flagelos e quando são numerosos possuem distribuição irregular. O estigma é bastante conspícuo, em geral alongado, sublinear, tem coloração avermelhada e situa-se próximo do pólo anterior da célula.

Ettl (1958) propôs que os gêneros Chlamydomonas e Chlorogonium fossem identificados não mais com base na forma da célula, mas no número de vacúolos contráteis por célula. Assim, as formas com numerosos vacúolos contráteis seriam representantes de Chlorogonium e aquelas com apenas dois, de Chlamydomonas. Acontece que as formas jovens de Chlorogonium não possuem mais do que dois vacúolos contráteis e as formas marinhas são desprovidas de tais vacúolos. A pouca consistência dessa proposta fez com que a maioria dos autores optasse pela forma de divisão celular como o caráter realmente diagnóstico dos dois gêneros. Segundo esta última proposta, em Chlamydomonas o plano de divisão celular é usualmente longitudinal e, ao final do processo, todos os protoplastos resultantes formam seu próprio aparelho flagelar e o estigma independentemente da célula-mãe. Em Chlorogonium, entretanto, o plano de divisão celular é transversal e ocorre retenção do aparelho flagelar e do estigma da célula-mãe por um dos protoplastos-filhos. Estas estruturas são retidas até a liberação dos protoplastos-filhos, quando então cada um formará suas próprias. Este último processo de diferenciação dos dois gêneros faz com que a identificação de seus representantes só seja possível quando se trabalhar com material vivo.

Chave para as espécies

1. Cloroplasto com 1 pirenóide

1. C. fusiforme

1. Cloroplasto sem pirenóide

2. Cloroplasto estendendo de um pólo ao outro da célula

3. C. heimii*

2. Cloroplasto ocupando apenas os $2 / 4$ medianos da célula

3. Célula medindo $17,5-20 \times 7,3-7,5 \mu \mathrm{m}$ 2. C. gracile

3. Célula medindo $44-48 \times 3,7-4 \mu \mathrm{m}$ 4. C. hiemale*

1. Chlorogonium fusiforme Matvienko, Uchen. Zap. Khark'kovsk. Gosud. Univ. Gor'kogo 3:62, fig. 43-44. 1938.

= Chlorogonium matvienkoi Skvortzov \& Noda, J. Jap. Bot. 42:198, fig. 25-27. 1967.

Figuras 27-28.

Célula amplamente fusiforme, pólo anterior truncado-arredondado, pólo posterior pontiagudo, ca.
$(12,5-) 30-37 \times(2,5-) 11-18 \mu \mathrm{m}, \mathrm{R} \mathrm{c} / 1=(5-) 8,2-10,1$; parede celular fina; flagelos $2,1 / 3-1 / 2$ do comprimento total da célula; cloroplasto 1 , parietal, em forma de calha, situado apenas em um lado da célula, pirenóide 1 , esférico, situado na metade anterior da célula, próximo do equador; estigma elíptico alongado, no terço anterior da célula, sobre o cloroplasto; vacúolos pulsáteis 1-2, quando 2, 1 situado na parte anterior e 1 na posterior. 
Hábitat: em um estancado no PEFI, sem qualquer outra indicação sobre o local nem sobre o hábito do material coletado; perifítica do Lago do Instituto de Astronomia, Geofísica e Ciências Atmosféricas.

Material examinado: BRASIL: São PAUlo: São Paulo, Parque Estadual das Fontes do Ipiranga, Lago do IAG, 1-VI-1997, R.Y. Honda s.n. (SP355512).

Desde que não há maior diferença entre os representantes de Chlorogonium matvienkoi Skvortzov \& Noda e os de C. fusiforme Matvienko, consideramos a primeira espécie sinônimo heterotípico da segunda.

2. Chlorogonium gracile Matvienko, Uchen. Zap. Khark'kovsk. Gosud. Univ. Gor'kogo 3:70, fig. 45. 1938.

= Chlorogonium nodeana Skvortzov \& Noda, J. Jap. Bot. 42:198, fig. 22. 1967.

Figura 29.

Célula amplamente fusiforme a elipsóide-fusiforme, pólo anterior truncado-arredondado, pólo posterior acuminado, 17,5-20 × 7,3-7,5 $\mu \mathrm{m}, \mathrm{R} \mathrm{c} / 1=2,4-2,7$; parede celular fina; flagelos desde $2 / 3$ até quase do comprimento da célula; cloroplasto 1, parietal, em forma de calha, situado apenas em um lado da célula ou estendendo-se por quase toda a célula, pirenóide ausente; estigma elíptico alongado, próximo da base do flagelo ou pouco mais para baixo, porém no quarto anterior da célula, sobre o cloroplasto; vacúolos pulsáteis 2 .

Hábitat: em um estancado no PEFI, sem qualquer outra indicação sobre o local nem sobre o hábito do material coletado; planctônica no hidrofitotério.

Material examinado: BRASIL: São PAUlo: São Paulo, Parque Estadual das Fontes do Ipiranga, hidrofitotério, 7-XI-1996, D.C. Bicudo \& L.L. Morandi s.n. (SP294903).

Não há diferença entre os representantes de Chlorogonium nodeana Skvortzov \& Noda e de C. gracile Matvienko, razão pela qual consideramos a primeira sinônimo heterotípico da segunda espécie.

3. Chlorogonium heimii* Bourrelly, Hydrobiologia 3:268, fig. 85-88. 1951.

= Chlorogonium saupaulensis Skvortzov \& Noda, J. Jap. Bot. 42:200, fig. 36. 1967.

Figura 30.

Célula fusiforme, levemente intumescida na porção mediana, pólos anterior e posterior truncadoarredondados, 34-38 × 6-6,8 $\mu \mathrm{m}, \mathrm{R} \mathrm{c} / 1=5,6-5,7$; parede celular fina; flagelos ca. $1 / 2$ do comprimento da célula; cloroplasto 1, parietal, em forma de calha, estendendo-se praticamente de um pólo ao outro, pirenóide ausente; estigma elíptico alongado, localizado na margem anterior do cloroplasto; vacúolos pulsáteis 2 , bem próximos do pólo anterior da célula.

Hábitat: em um estancado no PEFI, sem qualquer outra indicação sobre o local nem sobre o hábito do material coletado.

Material examinado: Skvortzov \& Noda, J. Jap. Bot. 42:200. 1967.

A grafia original do epíteto específico em Skvortzov \& Noda (1967) é saupaulensis, embora a correta fosse sancti-paulensis ou sanpaulensis, conforme recomenda [Rec. 60C.4. (d)] o Código Internacional de Nomenclatura Botânica (Greuter et al. 2000).

Não há diferença entre os representantes de Chlorogonium saupaulensis Skvortzov \& Noda e os de C. heimii Bourrelly. Por esta razão, preferimos considerar a primeira espécie sinônimo heterotípico da segunda.

4. Chlorogonium hiemale* Schiller, Österr. Bot. Z. 110:254, fig. 14a-h. 1954.

= Chlorogonium utriculariae Skvortzov \& Noda, J. Jap. Bot. 42:198, fig. 21. 1967.

Figura 31.

Célula fusiforme alongada, pólo anterior obliquamente truncado, pólo posterior mais afilado que $o$ anterior, levemente encurvado, 44,4-48 $\times 3,7-4 \mu \mathrm{m}$, $\mathrm{R} \mathrm{c} / 1=11-12$; parede celular fina; flagelos ca. $1 / 3$ do comprimento da célula; cloroplasto 1, parietal, em forma de calha, situado apenas de um lado da célula, não alcançando os pólos, pirenóide ausente; estigma elíptico, alongado, no quarto anterior da célula, sobre o cloroplasto; vacúolos pulsáteis 2 , indistintos.

Hábitat: planctônica em ambiente de água parada não especificado no Parque Estadual das Fontes do Ipiranga.

Material examinado: Skvortzov \& Noda, J. Jap. Bot. 42:198. 1967.

Não há diferença entre os representantes de Chlorogonium utriculariae Skvortzov \& Noda e os de $C$. hiemale Schiller, razão pela qual consideramos a primeira espécie sinônimo heterotípico da última.

\section{Chloromonas Gobi, emend. Wille}

Indivíduo monadóide de hábito solitário e vida livre extremamente parecido com os de Chlamydomonas. A célula mostra grande variação de forma em vista frontal (taxonômica), mas é, em geral, elipsóide, esférica 
ou quase, ovóide, elíptico-ovóide, fusiforme, subcilíndrica, não raro curvada e, até mesmo, um tanto assimétrica ou frontalmente comprimida. A parede celular pode ser muito fina e delicada ou espessa, grosseira, de espessura variada; e pode ou não apresentar uma papila anterior mediana. O cloroplasto é parietal, único por célula e pode ser poculiforme raso, urceolado ou revestir internamente quase toda a parede celular, sem deixar qualquer abertura. Não ocorre pirenóide, o que é a característica diagnóstica deste gênero e a única diferença entre ele e Chlamydomonas. Os dois flagelos possuem tamanhos iguais entre si, são homodinâmicos e inserem-se anterior e apicalmente na célula. Ocorrem em geral dois, raro um vacúolo contrátil por célula, situado(s) anterior e apicalmente na célula. Quando ocorre, o estigma é bastante conspícuo, tem forma variada desde praticamente esférica até linear, coloração avermelhada e situa-se anterior, mediana ou posteriormente na célula.

Autores mais antigos consideravam Chloromonas um subgênero de Chlamydomonas. Mais recentemente, entretanto, foram feitos vários experimentos com Chloromonas em laboratório utilizando os mais diversos meios de cultivo, de modo a demonstrar que a ausência de pirenóide é um fato notavelmente constante e suficiente para justificar a separação das espécies que não o possuem num gênero aparte, Chloromonas. Ao redor de 150 espécies de Chloromonas são atualmente conhecidas, as quais podem ser encontradas nas águas doces de quase todo o mundo. Ettl (1970) é a revisão taxonômica mais recente do gênero e contém uma chave para identificar as 134 espécies por ele reconhecidas. Outra revisão, Ettl (1983), permite identificar 139 espécies.

\section{Chave para as espécies}

1. Célula elipsóide-cilíndrica; papila cônica, pontiaguda

1. Célula elipsóide; papila cônica, arredondada
1. C. frigida

2. C. pumilio
1. Chloromonas frigida (Skuja) Gerloff \& Ettl in Ettl, Beih. Nova Hedwigia 34:81, pl. 17, fig. 1. 1970. Figura 32.

Célula elipsóide ou elipsóide-fusiforme, ambos pólos acuminado-arredondados ou pólo anterior acuminadoarredondado e posterior amplamente arredondado, 7-8 $\times 5-6 \mu \mathrm{m}$; parede celular fina, pólo anterior com 1 papila cônica, pontiaguda; flagelos 2 , aproximadamente do comprimento da célula; cloroplasto 1 , poculiforme, deixando apenas uma pequena abertura anterior; estigma punctiforme, situado no terço ou no quarto anterior da célula; vacúolos 2 , anteriores.

Hábitat: perifítica no Lago do Instituto de Astronomia, Geofísica e Ciências Atmosféricas.

Material examinado: BRASIL: São PAUlo: São Paulo, Parque Estadual das Fontes do Ipiranga, Lago do IAG, 1-VI-1997, R.Y. Honda s.n. (SP355514).

2. Chloromonas pumilio Ettl, Beih. Nova Hedwigia 34:104, pl. 25, fig. 3. 1970.

Figuras 33-34.

Célula elipsóide a elipsóide-cilíndrica, em geral dorsiventralmente simétrica, raro assimétrica, nunca fletida, ambos pólos arredondados, levemente acuminados, 6-9 × 1,5-2 $\mu \mathrm{m}$; parede celular fina, pólo anterior com 1 papila cônica, arredondada; flagelos 2 , aproximadamente do comprimento da célula; cloroplasto 1, parietal, em forma de calha, situado apenas em um lado da célula; estigma elíptico, situado no terço anterior da célula; vacúolos 2 , anteriores.

Hábitat: perifítica no Lago do Instituto de Astronomia, Geofísica e Ciências Atmosféricas.

Material examinado: BRASIL: São PAULO: São Paulo, Parque Estadual das Fontes do Ipiranga, Lago do IAG, 1-VI-1997, R.Y. Honda s.n. (SP355512).

Conforme a literatura, a célula de Chloromonas pumilio é sempre um pouco fletida dorsiventralmente. Entretanto, na amostra populacional atualmente examinada composta por 35 espécimes, só alguns poucos (cerca de $15 \%$ do total examinado) mostraram leve assimetria dorsiventral e até uma suave flexão. A maioria não apresentou qualquer flexão dorsiventral. $\mathrm{O}$ conhecimento atual desta espécie é bastante pequeno e reduz-se, ao que se sabe, à sua descrição original a partir de material da República Tcheca. Nestas condições, preferimos identificar o presente material com C. pumilio, porém, anotando a pequena incidência de espécimes de célula assimétrica na amostra populacional examinada. 
Phacotaceae

\section{Coccomonas Stein}

Indivíduo monadóide de hábito solitário e vida livre muito semelhante aos de Chlamydomonas. A característica mais importante e fundamental para a taxonomia deste gênero é a lórica no interior da qual vive a célula. Esta lórica é composta por uma só peça. É mais ou menos ampla, sólida, homogênea, às vezes levemente achatada e pode apresentar incrustação calcária e coloração que varia do amarelo-palha ao castanho-amarelado. Pode ser lisa ou apresentar decoração representada por grânulos, escrobículos ou estruturas vermiformes. No pólo anterior, existe uma abertura através da qual emergem os flagelos da célula. A célula mostra grande variação de forma em vista frontal (taxonômica), podendo ser elipsóide, ovóide ou gutuliforme, porém jamais assimétricas ou frontalmente comprimidas. A parede celular é sempre muito fina e delicada e pode apresentar uma papila anterior mediana. O cloroplasto é parietal, único por célula e pode ser poculiforme ou urceolado. O único pirenóide ocorre situado na parte basal do plasto. Os dois flagelos possuem tamanhos iguais entre si, são homodinâmicos e estão inseridos anterior e apicalmente na célula. Ocorrem comumente dois (raro um) vacúolos contráteis por célula, situados anterior e apicalmente na célula. Quando ocorre, o estigma é bastante conspícuo, tem forma variada desde quase esférica até linear, coloração avermelhada e situa-se anterior, mediana ou posteriormente na célula.

Apenas uma espécie identificada:

1. Coccomonas orbicularis Stein, Organ. Flagellaten 3(1): pl. 24, fig. 47-52. 1878.

Figuras 35-37.

Lórica pouco achatada em vista apical, elíptica ou quase, ovóide a cordiforme em vista frontal, pólo anterior nada ou muito pouco emarginado, pólo posterior arredondado, parede lisa ou finamente escrobiculada, amarela a acastanhada, com abertura flagelar, 6,1-7,8 $\times$ 5-6,7 $\mu \mathrm{m}$; célula ovóide, ovóide-arredondada a quase perfeitamente esférica, pólo anterior estreitado, 5-7,5 $\times$ 4-6 $\mu \mathrm{m}$; cloroplasto poculiforme, pirenóide 1, posterior; estigma na parte anterior da célula; vacúolos apicais 2 , anteriores; flagelos 2, mais longos que a lórica.

Hábitat: perifítica e planctônica no Lago do Instituto de Astronomia, Geofísica e Ciências Atmosféricas.

Material examinado: BRASIL: São PAULo: São Paulo, Parque Estadual das Fontes do Ipiranga, Lago do IAG, 1-VI-1997, R.Y. Honda s.n. (SP355512).

\section{Pteromonas Seligo}

Indivíduo monadóide muito parecido com os de Chlamydomonas, de hábito solitário e vida livre. A característica fundamental deste gênero para a taxonomia é a lórica no interior da qual vive a célula. Essa lórica é composta por duas peças (valvas) em geral idênticas uma à outra, uma das quais é dita dorsal e a outra ventral. A linha de sutura entre as valvas pode ser retilínea ou curva. A lórica é relativamente ampla, sólida, homogênea, mais ou menos achatada e apresenta formas extremamente bizarras, impossível de serem definidas geometricamente e, às vezes, até com estruturas espinescentes. No pólo anterior, existe uma abertura através da qual emergem os flagelos da célula. A célula mostra grande variação de forma em vista frontal (taxonômica), podendo ser elipsóide, ovóide ou gutuliforme, porém, jamais assimétrica ou frontalmente comprimida. A parede celular é sempre muito fina e delicada e pode apresentar uma papila anterior mediana. O cloroplasto é parietal, único por célula e pode ser poculiforme ou urceolado. $\mathrm{O}$ único pirenóide ocorre situado na parte basal do plasto. Os dois flagelos possuem tamanhos iguais entre si, são homodinâmicos e estão inseridos anterior e apicalmente na célula. Ocorrem comumente dois, raro um vacúolo contrátil por célula, situado(s) anterior e apicalmente na célula. $O$ estigma está geralmente presente e é bastante conspícuo, tem forma variada desde esférica até linear, coloração avermelhada e situa-se anterior, mediana ou posteriormente na célula.

Chave para as espécies

1. Lórica com processos basais cônicos pontiagudos 1. Pteromonas sp. 1

1. Lórica sem processos basais cônicos pontiagudos 2. Pteromonas sp. 2 


\section{Pteromonas sp. 1}

Figuras 38-39.

Lórica não achatada em vista apical, esférica ou quase em vista frontal, pólo anterior amplamente arredondado, pólo posterior arredondado, 1 processo basal, cônico, pontiagudo, estirado de cada lado, parede lisa, incolor, com abertura flagelar, ca. $15 \times 22,5 \mu \mathrm{m}$, $\mathrm{R} \mathrm{c} / 1=$ ca. 1 ; célula esférica ou quase, pólo anterior amplamente arredondado, ca. 13,3 $\mu \mathrm{m}$ diâm.; cloroplasto poculiforme, bastante aberto, pirenóide 1, mediano, deslocado para um dos lados; estigma na parte anterior da célula; vacúolos apicais 2, anteriores; flagelos 2, 2-2,5 vezes mais longos que a lórica.

Hábitat: planctônica no hidrofitotério.

Material examinado: BRASIL: SÃo PAUlo: São Paulo, Parque Estadual das Fontes do Ipiranga, hidrofitotério, 7-XI-1996, D.C. Bicudo \& L.L. Morandi s.n. (SP294903).

Encontramos apenas um exemplar deste tipo nas inúmeras preparações feitas. Este espécime não se encaixou na circunscrição de todas as espécies do gênero atualmente descritas e pode, muito provavelmente, ser representante de uma espécie nova. O exame de mais exemplares definirá a situação.

\section{Pteromonas sp. 2}

Figura 40.

Lórica levemente achatada em vista apical, esférica ou quase a aproximadamente cordiforme em vista frontal, pólo anterior medianamente emarginado a truncado-arredondado, pólo posterior acuminado a truncado-arredondado, sem qualquer processo basal, parede lisa, incolor, com abertura flagelar, ca. $17 \times 20 \mu \mathrm{m}$, $\mathrm{R}$ c/l $=0,8-0,9$; célula esférica ou quase, pólo anterior amplamente arredondado a pouco acuminado, em geral com papila, pólo posterior arredondado a acuminado, ca. 13 um diâm.; cloroplasto poculiforme, bastante aberto, pirenóide 1, mediano, deslocado para um dos lados; estigma na parte anterior da célula; vacúolos apicais 2 , anteriores; flagelos 2, 2-2,5 vezes mais longos que a lórica.

Hábitat: planctônica no Lago do Instituto de
Astronomia, Geofísica e Ciências Atmosféricas.

Material examinado: BRASIL: São PAUlo: São Paulo, Parque Estadual das Fontes do Ipiranga, Lago do IAG, 1-VI-1997, R.Y. Honda s.n. (SP355514).

Um único exemplar deste tipo foi encontrado nas inúmeras preparações feitas, o qual não se encaixou na circunscrição de qualquer espécie descrita de Pteromonas. Acredita-se, conseqüentemente, que possa se tratar de um representante de uma espécie que jamais foi descrita. Só o exame de maior quantidade de exemplares poderá definir esta situação.

\section{Volvocaceae}

\section{Pandorina Bory}

Colônias de vida livre, ativamente móveis, esféricas ou mais ou menos elipsóides. São, em geral, constituídas por oito ou 16, raro por quatro ou 32 indivíduos monadóides do tipo Chlamydomonas. Os indivíduos comprimem-se mutuamente formando uma espécie de pacote com um diminuto espaço no centro. A colônia é envolta por mucilagem copiosa, hialina e homogênea. As células são angulares e aproximadamente piriformes graças à compressão mútua. A face das células voltada para o exterior da colônia varia desde amplamente arredondada até mais ou menos truncada-arredondada e a face voltada para o interior da colônia é mais ou menos acuminada. Os dois flagelos são geralmente muito longos e inserem-se na face externa da célula, de onde saem aproximadamente paralelos da célula, muito próximo um do outro, mas podem ser até bastante divergentes após emergir da bainha colonial. O cloroplasto é único por célula e é sempre poculiforme; porém, o bordo pode ser liso ou franjado, isto é, constituído por inúmeras fitas mais ou menos paralelas entre si e voltadas para o pólo mais amplo da célula. Existe sempre um pirenóide, cuja situação é basal na célula. O estigma é único e ocorre na face da célula voltada para o ambiente. A parede celular é bem definida, embora fina e delicada. Ocorrem dois vacúolos contráteis na região próxima à base dos flagelos.

Apenas uma espécie identificada:

Figures 20-37. Volvocales species from the Parque Estadual das Fontes do Ipiranga. 20. Chlamydomonas gloeopara Rodhe \& Skuja. 21-22. Chlamydomonas planctogloea Skuja. 23-24. Chlamydomonas sagittula Skuja (from Skvortzov \& Noda 1967). 25-26. Chlamydomonas sordida Ettl. 27-28. Chlorogonium fusiforme Matvienko; 28 (from Skvortzov \& Noda 1967). 29. Chlorogonium gracile Matvienko (from Skvortzov \& Noda 1967). 30. Chlorogonium heimii Bourrelly (from Skvortzov \& Noda 1967). 31. Chlorogonium hiemale Schiller (from Skvortzov \& Noda 1967). 32. Chloromonas frigida (Skuja) Gerloff \& Ettl. 33-34. Chloromonas pumilio Ettl. 35-37. Coccomonas orbicularis Stein. Bars $=10 \mu \mathrm{m}$, except for fig. 29-31 $=20 \mu \mathrm{m}$. 

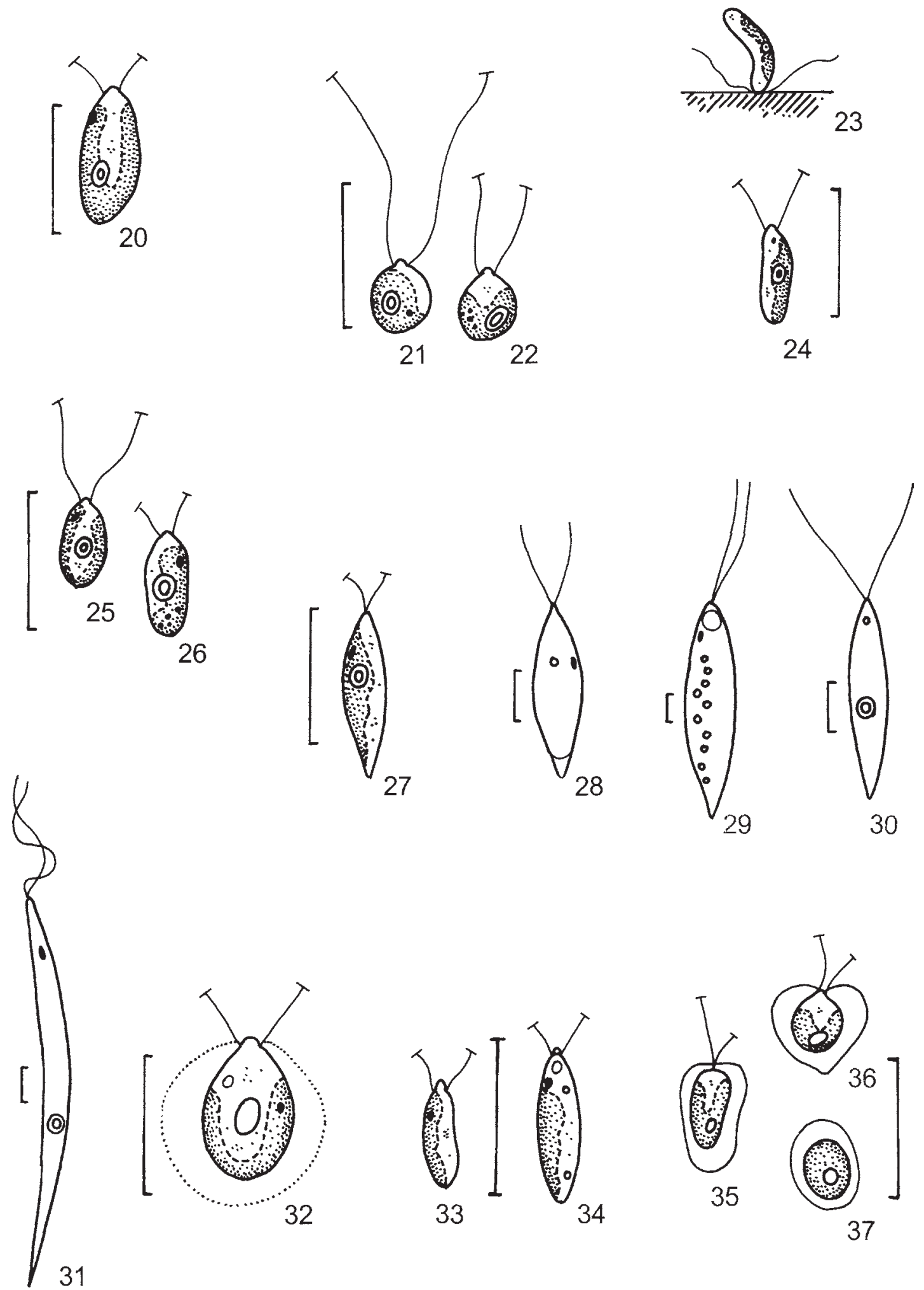

Figuras 20-37. Espécies de Volvocales do Parque Estadual das Fontes do Ipiranga. 20. Chlamydomonas gloeopara Rodhe \& Skuja. 21-22. Chlamydomonas planctogloea Skuja. 23-24. Chlamydomonas sagittula Skuja (de Skvortzov \& Noda 1967). 25-26. Chlamydomonas sordida Ettl. 27-28. Chlorogonium fusiforme Matvienko; 28 (de Skvortzov \& Noda 1967). 29. Chlorogonium gracile Matvienko (de Skvortzov \& Noda 1967). 30. Chlorogonium heimii Bourrelly (de Skvortzov \& Noda 1967). 31. Chlorogonium hiemale Schiller (de Skvortzov \& Noda 1967). 32. Chloromonas frigida (Skuja) Gerloff \& Ettl. $33-34$. Chloromonas pumilio Ettl. 35-37. Coccomonas orbicularis Stein. Barras $=10 \mu \mathrm{m}$, exceto fig. 29-31=20 $\mu \mathrm{m}$. 
1. Pandorina smithii Chodat, Recueil Trav. Crypt. 7, pl. 1, fig. 14. 1931.

Figura 41.

Colônias esféricas ou quase, ca. $39 \mu \mathrm{m}$ diâm., em geral com 16 células compactamente arranjadas, mutuamente comprimidas, deixando um pequeno espaço vazio no centro, mucilagem abundante, firme, homogênea, incolor; células obovóides a amplamente cônicas, raro um tanto arredondadas, ca. $9 \times 10 \mu \mathrm{m}$; cloroplasto poculiforme, pirenóide 1, basal; estigma em geral grande, na parte anterior mais bojuda da célula; vacúolos apicais 2, anteriores; flagelos 2, emergindo paralelos da mucilagem, depois amplamente divergentes, ca. 2 vezes o comprimento da célula.

Hábitat: planctônica no Lago do Instituto de Astronomia, Geofísica e Ciências Atmosféricas.

Material examinado: BRASIL: São PAUlo: São Paulo, Parque Estadual das Fontes do Ipiranga, Lago do IAG, 1-VI-1997, R.Y. Honda s.n. (SP355512).

A única diferença entre esta espécie e Pandorina morum (O.F. Müller) Bory é o tipo de cloroplasto, que na última é longitudinalmente franjado.

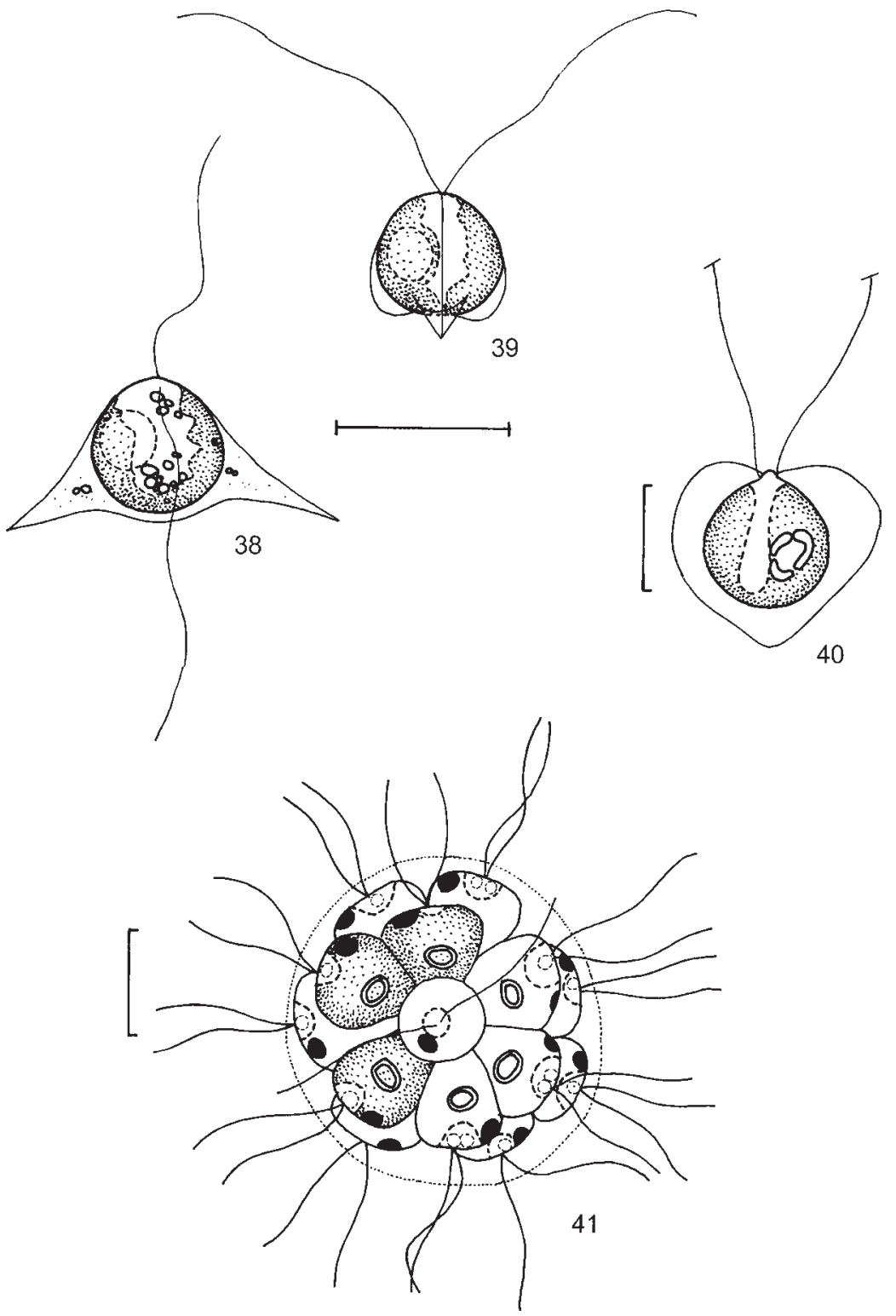

Figuras 38-41. Espécies de Volvocales do Parque Estadual das Fontes do Ipiranga. 38-39. Pteromonas sp. 1. 40. Pteromonas sp. 2. 41. Pandorina smithii Chodat. Barras $=10 \mu \mathrm{m}$.

Figures 38-41. Volvocales species from the Parque Estadual das Fontes do Ipiranga. 38-39. Pteromonas sp. 1. 40. Pteromonas sp. 2. 41. Pandorina smithii Chodat. Bars $=10 \mu \mathrm{m}$. 
Chave geral

1. Células organizadas em colônias graças à presença de mucilagem comum

(Pandorina) P. smithii

1. Células isoladas, não organizadas em colônias

2. Célula no interior de uma lórica

3. Lórica constituída por 1 única peça

3. Lórica constituída por 2 peças

(Coccomonas) C. orbicularis

4. Lórica com processos basais cônicos pontiagudos

(Pteromonas)

4. Lórica sem processos basais cônicos pontiagudos

Pteromonas sp. 1

Pteromonas sp. 2

2. Célula destituída de lorica

5. Célula com 4 flagelos

(Carteria)

6. Célula com estigma

7. Cloroplastos numerosos, discóides

C. polychloris

7. Cloroplasto 1 , urceolado

8. Célula esférica ou quase

9. Pirenóide pequeno, esférico

C. globulosa*

9. Pirenóide grande, esférico ou transversalmente elíptico

10. Pólo anterior da célula com papila hemisférica

C. multifilis

10. Pólo anterior da célula destituído de papila

C. sanpaulensis

8. Célula elipsóide, elipsóide-cilíndrica a oblonga

11. Papila ampla, pouco proeminente; pirenóide grande

11. Papila cônica a hemisférica, bastante proeminente; pirenóide pequeno

12. Célula elipsóide-cilíndrica, quase oblonga

C. platyrhyncha*

12. Célula amplamente elipsóide

C. lunzensis*

6. Célula sem estigma

13. Cloroplastos numerosos, discóides

C. plana*

13. Cloroplasto 1, urceolado

C. hiemale*

élula com 2 flagelos

14. Divisão celular no plano longitudinal; célula com pirenóide

15. Cloroplasto com 1 pirenóide

(Chlorogonium)

15. Cloroplasto sem pirenóide

C. fusiforme

16. Cloroplasto estendendo de um pólo ao outro da célula

C. heimii*

16. Cloroplasto ocupando apenas os $2 / 4$ medianos da célula

17. Célula medindo $17,5-20 \times 7,3-7,5 \mu \mathrm{m}$

C. gracile

17. Célula medindo 44-48 $\times 3,7-4 \mu \mathrm{m}$

C. hiemale*

14. Divisão celular no plano transversal

18. Célula sem pirenóide

(Chloromonas)

19. Célula elipsóide-cilíndrica; papila cônica, pontiaguda

C. frigida

19. Célula elipsóide; papila cônica, arredondada

C. pumilio

18. Célula com pirenóide

20. Cloroplasto em forma de $\mathrm{H}$

20. Cloroplasto poculiforme, ciatiforme ou em forma de calha

21. Cloroplasto em forma de calha

22. Célula elipsóide-ovóide a nitidamente ovóide

C. sordida

22. Célula elipsóide-cilíndrica, um tanto baciliforme

C. sagittula

21. Cloroplasto poculiforme ou ciatiforme

23. Estigma situado na metade posterior da célula

C. planctogloea

23. Estigma situado no terço anterior da célula

24. Pirenóide situado no espessamento mais ou menos mediano do cloroplasto

C. gloeopara

24. Pirenóide situado na porção basal do cloroplasto

25. Célula 9-12 $\times 6-8,5 \mu \mathrm{m} ; \mathrm{R} \mathrm{c} / 1=1,3-2$

C. debaryana

25. Célula 6-8 $\times 5-5,5 \mu \mathrm{m} ; \mathrm{R} \mathrm{c} / 1=1-1,1$

C. epibiotica 
Táxons excluídos - Os seguintes materiais deixaram de ser considerados no presente trabalho. Após cada nome consta a razão de sua não-inclusão presente.

Carteria utriculariae* Skvortzov, Bol. Soc. Bot. La Libertad, 2:6, fig. 5. 1970.

A ausência de material original depositado em herbário aliada à não-coleta de novos exemplares da espécie e à descrição e ilustração relativamente pobres em detalhes morfológicos não permitiram reavaliação taxonômica do material.

Carteria utriculariae* Skvortzov \& Noda, Sci. Rep. Niigata Univ., Ser. D 4:29, fig. 5. 1981 (grafia no trabalho: Carteria utrinulariae).

A ausência de material original depositado em herbário somada à não-coleta de novos exemplares da espécie e à descrição e ilustração relativamente pobres em detalhes morfológicos não permitiram reavaliação taxonômica do material.

\section{Referências bibliográficas}

BOURRELLY, P.C. 1972. Les algues d'eau douce: initiation à la systématique: les algues vertes. Éditions N. Boubée \& Cie., Paris. v.1, 572 p. (Reimpressão revista e aumentada).

CROSSETTI, L.O. 2002. Efeitos do empobrecimento experimental de nutrientes sobre a comunidade fitoplanctônica em reservatório eutrófico raso, Lago das Garças, São Paulo. Dissertação de mestrado, Universidade de São Paulo, Ribeirão Preto.

ETTL, H. 1958. Zur Kenntnis der Klasse Volvophyceae, 1. In Algologische Studien (J. Komárek \& H. Ettl, eds.). Verlag der Tscheckoslovakischen Akademie der Wissenschaften, Praha, p.207-289.

ETTL, H. 1970. Die Gattung Chloromonas Gobi emend. Wille. Nova Hedwigia 34:1-283.

ETTL, H. 1976. Die Gattung Chlamydomonas. Nova Hedwigia, suppl. 49:1-1122.

ETTL, H. 1983. Chlorophyta, 1: Phytomonadina. In Süsswasserflora von Mitteleuropa (H. Ettl, J. Gerloff, H. Heynig \& D. Mollenhauer, eds.). Gustav Fischer, Stuttgart, v.9, p.1-807.

FIDALGO, O. \& BONONI, V.L.R. (cords.). 1984. Técnicas de coleta, preservação e herborização de material botânico. (Manual n.4). Instituto de Botânica, São Paulo.
GENTIL, R.C. 2000. Variação sazonal do fitoplâncton de um lago subtropical eutrófico e aspectos sanitários, São Paulo, SP. Dissertação de mestrado, Universidade de São Paulo, São Paulo.

GREUTER, W., MCNEILL, J., BARRIE, F.R., BURDET, H.M., DEMOULIN, V., FILGUEIRAS, T.S., NICOLSON, D.H., SILVA, P.C., SKOG, J.E., TREHANE, P., TURLAND, N.J. \& HAWKSWORTH, D.L. 2000. International Code of Botanical Nomenclature (Saint Louis Code). Regnum Vegetabile 138. Koeltz Scientific Books, Königstein.

LOPES, M.R.M. 1999. Eventos perturbatórios que afetam a biomassa, a composição e a diversidade de espécies do fitoplâncton em um lago tropical oligotrófico raso (Lago do Instituto Astronômico e Geofísico, São Paulo, SP). Tese de doutorado, Universidade de São Paulo, São Paulo.

MILANEZ, A.I., BICUDO, C.E.M., VITAL, D.M. \& GRANDI, R.A.P. 1990. Criptógamos do Parque Estadual das Fontes do Ipiranga, São Paulo, SP: planejamento. Hoehnea 17:43-49.

MOURA, A.T.N. 1996. Estrutura e dinâmica da comunidade fitoplanctônica numa lagoa eutrófica, São Paulo, SP, Brasil, a curtos intervalos de tempo: comparação entre épocas de chuva e seca. Dissertação de mestrado, Universidade Estadual Paulista, Rio Claro.

SKVORTZOV, B.V. 1967. Algological notes, 1-3. The Bulletin of the Japanese Society of Phycology 15:37-44.

SKVORTZOV, B.V. 1970. On species of genus Carteria Dies., fam. Chlamydomonadaceae Pascher, Volvocineae, Chlorophyta recorded in 1962-1966 in São Paulo (Brasil) and also in Hong Kong and Texas (USA). Boletín de la Sociedad Botánica de La Libertad 2:3-11.

SKVORTZOV, B.V. \& NODA, M. 1967. On species of a green flagellata of the genus Chlorogonium Ehr., Volvocineae, Chlorophyceae from Japan, Hong Kong and Brasil. Journal of Japanese Botany 42:193-200.

SKVORTZOV, B.V. \& NODA, M. 1969. On new colourless flagellata with refractive granules and cytoprokt of class Chloromonadaceae from subtropics of Brasil, South America. Sciences Report of Niigata University, Ser. D 6:97-100.

SKVORTZOV, B.V. \& NODA, M. 1981. On species of genus Carteria (Chlamydomonadaceae, Volvocineae) recorded in 1962-1966 in Hong Kong, Texas U.S.A. and in Brasil. Sciences Report of Niigata University, Ser. D 4:27-33.

TUCCI, A. 2002. Sucessão da comunidade fitoplanctônica de um reservatório urbano e eutrófico, São Paulo, SP, Brasil. Tese de doutorado, Universidade Estadual Paulista, Rio Claro.

VERCELLINO, I.S. 2001. Sucessão da comunidade de algas perifíticas em dois reservatórios do Parque Estadual das Fontes do Ipiranga, São Paulo: influência do estado trófico e período climatológico. Dissertação de mestrado, Universidade Estadual Paulista, Rio Claro. 